\title{
Stroke and Stroke-like Episodes in Muscle Disease
}

\author{
Josef Finsterer*
}

\author{
Krankenanstalt Rudolfstiftung, Vienna, Danube University Krems, Austria
}

\begin{abstract}
Background: Though not obvious at a first glance, myopathies may be associated with ischemic stroke. Strokelike episodes resemble ischemic stroke only to some extent but are a unique feature of certain mitochondrial disorders with a pathogenesis at variance from that of ischemic stroke. Only limited data are available about ischemic stroke in primary myopathies and the management of stroke-like episodes in mitochondrial disorders. This review aims to summarize and discuss current knowledge about stroke in myopathies and to delineate stroke-like episodes from ischemic stroke.
\end{abstract}

Methods: Literature review via PubMED using the search terms "stroke", "cerebrovascular", "ischemic event", "strokelike episode", "stroke-mimic", "mitochondrial disorder".

Results: Stroke in myopathies is most frequently cardioembolic due to atrial fibrillation or atrial flutter, dilated cardiomyopathy, or left-ventricular hypertrabeculation (noncompaction). The second most frequent cause of stroke in myopathies is angiopathy from atherosclerosis or vasculitis, which may be a feature of inflammatory myopathies. Atherosclerosis may either result from classical risk factors, such as diabetes, arterial hypertension, hyperlpidemia, or smoking, associated with muscle disease, or may be an inherent feature of a mitochondrial disorder. In case of severe heart failure from cardiomyopathy as a manifestation of muscle disease low flow infarcts may occur. Thrombophilic stroke has been described in polymyositis and dermatomyositis in association with anti-phospholipid syndrome. Stroke-like episodes occur particularly in mitochondrial encephalopathy, lactacidosis and stroke-likeepisode syndrome but rarely also in Leighsyndrome and other mitochondrial disorders. Stroke-like episodes are at variance from ischemic stroke, pathogenically, clinically and on imaging. They may be the manifestation of a vascular, metabolic or epileptic process and present with predominantly vasogenic but also cytotoxic edema on MRI. Differentiation between ischemic stroke and stroke-like episodes is essential in terms of management and prognosis. Management of ischemic stroke in patients with myopathy is not at variance from the treatment of ischemic stroke in non-myopathic patients. There is no standardized treatment of strokelike episodes but there is increasing evidence that these patients profit from the administration of L-arginine and consequent antiepileptic treatment if associated with seizure activity.

Conclusions: Ischemic stroke may be a complication of myopathy and needs to be delineated from stroke-like episodes, which are unique to mitochondrial disorders, particularly mitochondrial encephalopathy, lactacidosis and strokelikeepisode syndrome. Ischemic stroke in myopathies is most frequently cardioembolic and treatment is not at variance from non-myopathic ischemic stroke. Treatment of stroke-like episodes is not standardized but seems to respond to Larginine and adequate antiepileptic treatment.

Keywords: Cerebral infarction, ischemic stroke, genetics, cardiomyopathy, noncompaction, atrial fibrillation, neuromuscular disorder, MELAS-syndrome, stroke-like episode.

\section{INTRODUCTION}

Myopathies are a heterogeneous group of neurological disorders primarily affecting the striated skeletal muscle due to mutations in genes encoding for components of the myocyte (primary myopathies) or due to secondary affection of the muscle within the scope of a general disorder primarily affecting organs other than the muscle (secondary myopathies). Ischemic stroke is one of the most prevalent neurological disorders and the third most frequent cause of death [1]. Stroke-like episodes (SLEs) are phenotypic features predominantly of mitochondrial disorders (MIDs), most

*Address correspondence to this author at the Postfach 201180 Vienna, Austria, Europe; Tel: +43-1-71165-92085; Fax: +43-1-4781711;

E-mail: fifigs1@yahoo.de frequently mitochondrial encephalopathy, lactacidosis, SLE (MELAS)-syndrome, and mimic the clinical manifestations of ischemic stroke to some extent [2]. Their prevalence is much lower than that of ischemic stroke. Though myopathies do not seem to be obviously associated with stroke at a first glance, there is a strong causal relation if there is cardiac involvement in myopathies, if the underlying cause of myopathy is a MID, or if the muscle disease is part of a multisystem disease, which also manifests with classical risk factors for ischemic stroke, such as diabetes, hyperlipidemia, or arterial hypertension. This review aims to give an overview about the current knowledge concerning the relation between muscle disease and ischemic stroke and SLEs with regard to pathogenesis, diagnosis, treatment and outcome. 


\section{CLASSIFICATION OF ISCHEMIC STROKE}

Ischemic stroke is generally graded according to the TOAST-classification, which denotes five subtypes of is chemic stroke following its pathogenesis: 1) atherosclerosis of large arteries 2) cardioembolism, 3) small-vessel occlusion, 4) stroke due to other etiology (vasculitis, dissection, coagulation disorder etc.), and 5) stroke of undetermined etiology [3]. Narrowing or occlusion of large extra- or intracerebral arteries by arteriopathy or embolism leads to ischemia of the downstream vascular territory. Narrowing or occlusion of small intra-cerebral arteries by arteriopathy or embolism leads to ischemia only of a small vascular territory, morphologically manifesting as white matter lesions or lacunas. In addition to cardioembolic or angiopathic causes, ischemic stroke may result from hemodynamic, thrombophilic, or metabolic abnormalities [4].

\section{RISK FACTORS FOR STROKE IN MYOPATHIES}

Risk factors for the development of ischemic stroke in myopathies are cardiac disease, frequently associated with myopathies, or atherosclerosis either due to classical risk factors from a multisystem disease or due to a manifestation of a MID [5]. Other risk factors may be low output failure, arterial hypotension or thrombophilic conditions. Predisposing for stroke may be also MELAS-syndrome, which is pathogenically characterised by arteriopathy [6] and frequently also presents with metabolic muscle disease or compromised cardiac function. Cardiac involvement predisposing for ischemic stroke includes sarrhythmias, such as atrial fibrillation, heart failure from hypertrophic cardiomoypathy, dilative cardiomyopathy, restrictive cardiomoypathy, or noncompaction without heart failure. Another risk factor for ischemic stroke may be cryptogenic intraventricular thrombus formation in the absence of atrial fibrillation or heart failure, as has been described in Duchenne muscular dystrophy (DMD) [7].

\section{$\begin{array}{lllll}\text { ETIOLOGY OF ISCHEMIC STROKE IN } & \end{array}$ MYOPATHIES}

\section{A) Cardioembolism}

Cardiac disease is a frequent feature of many of the primary muscle disorders. Cardiac involvement in myopathies may manifest as cardiac conduction disorder or cardiomyopathy. Conduction disorders may manifest as impulse generation or impulse conduction abnormality.

\section{Atrial Fibrillation/Flutter}

The arrhythmia most frequently associated with stroke in myopathies is atrial fibrillation. Impaired contractility of the left atrial wall favors thrombus formation within the left

Table 1. Myopathies in which Atrial Fibrillation or Atrial Flutter has been Found

\begin{tabular}{|c|c|c|}
\hline Myopathy & Reference & Stroke \\
\hline \multicolumn{3}{|l|}{ Primary myopathies } \\
\hline \multicolumn{3}{|l|}{ Muscular dystrophies } \\
\hline Dystrophinopathies & {$[9,10,12]$} & {$[9,10]$} \\
\hline Emery-Dreifuss muscular dystrophy 1 (emerin) & {$[8]$} & {$[8]$} \\
\hline Emery-Dreifuss muscular dystrophy $2(\operatorname{laminA} / \mathrm{C})$ & {$[8]$} & {$[8]$} \\
\hline \multicolumn{3}{|l|}{ Limb girdle muscular dystrophies } \\
\hline LGMD1B & {$[76-81]$} & NR \\
\hline \multicolumn{3}{|l|}{ Myotonic dystrophies } \\
\hline Myotonic dystrophy 1 & {$[12,82-84]$} & {$[11,12]$} \\
\hline Myotonic dystrophy 2 & {$[13]$} & {$[13]$} \\
\hline Facio-scapulo-humeral muscular dystrophy & [85] & NR \\
\hline Myofibrillar myopathies & [86] & NR \\
\hline Desmin myopathy & {$[87,88]$} & NR \\
\hline Rigid spine syndrome & [89] & NR \\
\hline Danon's disease & [90] & [90] \\
\hline Barth syndrome & {$[4]$} & NR \\
\hline McLeod syndrome & {$[91,92]$} & NR \\
\hline Congenital myopathies & {$[93]$} & NR \\
\hline \multicolumn{3}{|l|}{ Metabolic myopathies } \\
\hline Glycogenosis & [94] & NR \\
\hline Mitochondrial myopathy & [95] & NR \\
\hline Congenital fiber type dysproportion & {$[96]$} & NR \\
\hline Epidermiolysis bullosa simplex & {$[97]$} & NR \\
\hline \multicolumn{3}{|l|}{ Secondary myopathies } \\
\hline Polymyositis & [98] & NR \\
\hline Dermatomyositis & {$[14]$} & [14] \\
\hline Colchicine-induced myopathy & [99] & NR \\
\hline Hypothyroid myopathy & {$[100]$} & NR \\
\hline Hyperthyroid myopathy & [101] & NR \\
\hline
\end{tabular}


atrium or the left atrial appendage, which are consecutively flushed out to the arterial bed, including the cerebral arteries. Myopathies in which atrial fibrillation has been described are listed in Table 1. That stroke has not been reported in each of the myopathies listed in this table may be due to the poor follow-up of most myopathy patients. In a series of 11 patients with Emery-Dreyfuss muscular dystrophy ischemic stroke has been reported in four of them who presented with atrial fibrillation or flutter. The outcome was not reported but three of these patients had autosomal dominant (Lamin A/C) and one X-linked (emerin) Emery-Dreyfuss muscular dystrophy [8]. Stroke was also reported during an episode of atrial fibrillation in a patient with Becker muscular dystrophy [9]. Among five patients with DMD, one experienced ischemic stroke [10]. He had a history of atrial fibrillation but also of dilative cardiomyopathy. Transient ischemic attack and stroke have been also described in a patient with myotonic dystrophy 1 in whom paroxysmal atrial fibrillation was recorded [11]. Screening of 52 patients with DMD, 61 with myotonic dystrophy 1 and 14 with Becker muscular dystrophy revealed atrial flutter in 3 with MD1, and 1 with DMD. Atrial fibrillation was detected in none of them. Only one of the included patients developed ischemic stroke during atrial flutter [12]. In a study on 38 patients with myotonic dystrophy 2 , five had developed ischemic stroke. Two of these patients had atrial fibrillation with normal systolic function [13]. Ischemic stroke may be associated also with secondary myopathy. In a patient with dermatomyositis, restrictive cardiomyopathy, and atrial fibrillation, a transient ischemic attack has been reported [14]. Arrhythmias leading to cardioembolism may also result from hyperkaliemia following rhabdomyolysis.

\section{Dilative Cardiomyopathy}

Dilative cardiomyopathy is prone to heart failure and arrhythmias [15]. Thus patients with myopathy in whom cardiac involvement manifests as dilative cardiomyopathy are also at increased risk to thromboembolism. Though the exact pathogenesis of the intracardiac thrombus formation in dilative cardiomyopathy remains elusive it can be speculated that impaired hemodynamics activates the coagulation cascade. In addition to embolism, dilative cardiomyopathy may be associated with arterial hypotension and thus cerebral hypoperfusion. Studies about myopathies with dilative cardiomyopathy which were associated with stroke are listed in Table 2. According to these studies ischemic stroke has been reported in two patients with DMD [16]. Both patients experienced ischemic stroke at age $21 \mathrm{y}$ in sinusrhythm but with an ejection fraction (EF) below $20 \%$ and together with increased thrombin-ATIII complexes and increased D-dimer.

Table 2. Myopathies Associated with Dilative Cardiomyopathy and Stroke

\begin{tabular}{|c|c|c|}
\hline Myopathy & Reference & Stroke \\
\hline \multicolumn{3}{|l|}{ Muscular dystrophies } \\
\hline Dystrophinopathies & {$[16,102]$} & {$[10,16,17]$} \\
\hline Limb girdle muscular dystrophies & {$[103,104]$} & NR \\
\hline Laminopathies & {$[81,105-107]$} & NR \\
\hline LGMD1B & {$[108]$} & NR \\
\hline LGMD1E & [108] & NR \\
\hline LGMD2D-F & {$[108]$} & NR \\
\hline LGMD2I & {$[108,109]$} & NR \\
\hline \multicolumn{3}{|l|}{ Congential muscular dystrophies } \\
\hline Fukuyama type CMD & {$[110]$} & NR \\
\hline Merosin-deficient CMD & [111] & NR \\
\hline Myofibrillar myopathies & {$[112]$} & NR \\
\hline Desminopathy & [113] & NR \\
\hline \multicolumn{3}{|l|}{ Other } \\
\hline Vacuolar myopathy (LAMP2) & {$[114,115]$} & NR \\
\hline Barth syndrome & {$[116,117]$} & {$[18]$} \\
\hline McLeod syndrome & {$[118]$} & NR \\
\hline Reducing body myopathy & {$[119,120]$} & NR \\
\hline \multicolumn{3}{|l|}{ Congenital myopathies } \\
\hline Nemaline myopathy & {$[121,122]$} & NR \\
\hline Central core disease & {$[123]$} & NR \\
\hline Centronuclear myopathy & {$[124,125]$} & NR \\
\hline Congenital fiber type dysproportion & {$[96,126,127]$} & NR \\
\hline \multicolumn{3}{|l|}{ Metabolic myopathies } \\
\hline Glycogenosis type IV & {$[128]$} & NR \\
\hline Primary carnitin deficiency & [129] & NR \\
\hline Mitochondrial disorders & {$[130,131]$} & NR \\
\hline Kearns-Sayre syndrome & [132] & NR \\
\hline
\end{tabular}


The second patient had experienced a TIA already five months prior to the stroke. Ischemic stroke was also reported in a 13 yo DMD patient in sinusrhythm and with an EF of 35$40 \%$ [17]. Five months later he experienced a second stroke in the same vascular territory as before [17]. Stroke was also reported in another five patients with DMD and dilative cardiomyopathy aged 16-20y of whom one presented with atrial fibrillation on ECG [10]. Additionally, stroke has been described in a patient with Barth syndrome and dilative cardiomyopathy who was in sinusrhythm at the time of the event [18].

\section{Left Ventricular Hypertrabeculation (LVHT, Noncom- paction)}

LVHT is an increasingly recognized abnormality of the left ventricular myocardium, characterised by a two-layered structure mainly of the apex and the lateral wall. The epicardial layer consists of normal myocardium whereas the endocardial layer has a spongy-like structure of interwoven myocardial strings, which are all covered with endocardium $[19,20]$. LVHT is most frequently diagnosed on echocardiography if there are more than three single trabeculations at end-diastole, if there is the two-layered structure at endsystole, and if the perfusion of the intertrabecular spaces from the ventricular side can be visualized at end-diastole [21]. Depending on the study, LVHT is associated with myopathy in up to $80 \%$ of the cases. Most frequently LVHT is associated with Barth syndrome and MIDs [22]. Myopathies in which LVHT has been described so far are listed in Table 3. Frequent complications of LVHT are heart failure, ventricular arrhythmias, and stroke or embolism [22]. Though stroke has been reported in a number of LVHT patients who were not neurologically investigated (Table 4), it was described only in two patients with neuromuscular disorder and LVHT so far [Finsterer et al., submitted], suggesting that stroke in LVHT patients with myopathy is underes- timated. One reason for the low rate of stroke in LVHTpatients with myopathy is that usually LVHT-patients are not referred to the neurologist, why a possible neuromuscular disorder frequently remains undetected. Whether the stroke risk and prevalence of stroke is truly increased in patients with LVHT is under debate. There are studies, which do not report an increased incidence of stroke among LVHT patients [23-25], whereas others do [26-29]. In a study on 229 patients with LVHT but without atrial fibrillation or flutter four experienced ischemic stroke during a mean follow-up of $7.3 y$ [23]. In a study on 62 LVHT patients the incidence of stroke was $10 \%$ compared to $15 \%$ in controls matched for age, sex and systolic function [24]. Arguments for an increased stroke risk are that reduced perfusion of intertrabecular spaces, occurrence of ventricular arrhythmias, and increased incidence of heart failure favor thrombus formation. Nevertheless, there is no general need to put LVHT patients on oral anticoagulation (OAC) unless classical indications for OAC are present.

\section{B) Macroangiopathy}

\section{Atherosclerosis}

In a patient with MELAS-syndrome due to the heteroplasmic transition $\mathrm{m} .617 \mathrm{G}>\mathrm{A}$ in the tRNA(Phe) gene recurrent ischemic strokes occurred, which were accompanied by transient occlusion of the middle cerebral, anterior cerebral and internal carotid arteries [30]. Strokes were presumably attributed to artery-to-artery embolisms originating from the carotid artery stenosis [30]. The cause of the carotid internal stenosis was not found. Since classical risk factors for atherosclerosis were absent, carotid internal artery stenosis was attributed to the MID. Atherosclerosis in the absence of classical risk factors for macroangiopathy has been also reported in other patients with MID [5]. Macroangiopathic ischemic stroke must be clearly delineated from SLE, which

Table 3. Myopathies Associated with Noncompaction

\begin{tabular}{|c|c|c|}
\hline Myopathy & Reference & Stroke \\
\hline \multicolumn{3}{|l|}{ Muscular dystrophies } \\
\hline Myotonic dystrophy I & {$[133]$} & NR \\
\hline Dystrophinopathies & [134] & NR \\
\hline Barth syndrome & {$[18]$} & {$[18]$} \\
\hline Zaspopathy & {$[135]$} & NR \\
\hline Laminopathies & [136] & NR \\
\hline Dystrobrevinopathies & {$[137]$} & NR \\
\hline Oculopharyngeal muscular dystrophy & {$[138]$} & NR \\
\hline \multicolumn{3}{|l|}{ Metabolic myopathies } \\
\hline Mitochondrial disorder & {$[139]$} & [Finsterer, submitted] \\
\hline Myoadenylate-deaminase deficiency & {$[140]$} & NR \\
\hline Glycogenosis type II (M. Pompe) & [unpublished] & NR \\
\hline \multicolumn{3}{|l|}{ Non-myopathic } \\
\hline Charcot-Marie-Tooth neuropathy type 1A & [141] & NR \\
\hline Friedreich ataxia & [unpublished] & NR \\
\hline
\end{tabular}


Table 4. Studies Reporting Stroke in LVHT Patients

\begin{tabular}{|c|c|c|c|}
\hline Study & NOP investigated & NOP stroke & Additional findings \\
\hline Münkle et al. 2010 [142] & 1 & 1 & Severe heart failure \\
\hline Mello et al. 2010 [143] & 1 & 1 & Chagas disease \\
\hline Stöllberger et al. 2010 [144] & 1 & 1 & Heart transplantation \\
\hline Vatthyam et al. 2009 [145] & 1 & 1 & Fatal acute heart failure, \\
\hline Steffel et al. 2009 [146] & 78 & Not reported & Risk of embolism associated with ECG \\
\hline Stanton et al. 2009 [147] & 30 & 2 & Death only with decreased systolic function \\
\hline Sahin \& Karsidag 2009 [28] & 1 & 1 & None \\
\hline Fazio et al. 2009 [26] & 1 & 1 & Not reported \\
\hline Fazio et al. 2008 [23] & 229 & 4 & Decreased systolic function ( $50 \%$ of pat.) \\
\hline Finsterer et al. 2008 [24] & 104 & $16(15 \%)$ & At least 1 classical risk factor in 15 pat. \\
\hline Sir et al. 2008 [29] & 1 & 1 & None \\
\hline Oduncu et al. 2008 [27] & 1 & 1 & Bivenricular noncompaction \\
\hline Baez-Escudero et al. 2008 [148] & 1 & 1 & Systolic dysfunction \\
\hline Finsterer et al. 2008 [149] & 1 & 1 & Stroke-like-episodes, endocarditis \\
\hline Nakajima et al. 2007 [150] & 1 & 1 & Decreased systolic function \\
\hline Celebi et al. 2007 [151] & 1 & 1 & Essential thrombocytosis \\
\hline Fernandez Sanchez et al. 2006 [152] & 1 & 1 & Pregnant women shortly before delivery \\
\hline Walpot et al. 2005 [153] & 1 & 1 & Not reported \\
\hline Stöllberger \& Finsterer2005 [25] & 62 & 6 & Incidence of stroke lower than in controls \\
\hline Hascelik et al. 2003 [154] & 1 & 1 & 18 months-old girl with elevated factor VIII" \\
\hline
\end{tabular}

NOP: Number of patients

is speculated to be microangiopathy-related or due to nonischemic neurovascular events [30].

\section{Vasculitis}

Vasculitis of the large arteries associated with stroke has been particularly reported in inflammatory myopathies, such as polymyositis or dermatomyositis. A patient with polymyositis experienced an ischemic stroke and myocardial infarction shortly after high dose steroids [31]. Whether stroke in this patient was due to vasculitis or due to steroid-induced diabetic angiopathy remains speculative [31]. Ischemic stroke was also reported in a 47yo female with dermatomyositis. Stroke in this patient was attributed to cerebral vasculitis, which was confirmed by conventional angiography and brain biopsy [32]. Dermatomyositis and vasculitis responded favorably to cyclophosphamide [32]. Ischemic stroke was additionally reported in a 47yo female under intravenous immunoglobulines (IVIG) for dermatomyositis [33]. Whether stroke in this patient was truly due to vasculitis or a side effect of IVIG remained speculative [33]. Stroke in addition to livedo reticularis, recurrent abortions, and mitral regurgitation, was also described in a female with polymyositis/dermatomyositis, lupus erythematosus, and antiphospholipid syndrome [34]. In a recent study on patients with dermatomyositis or polymyositis cerebrovascular events were found in $0.51 \%$ of the cases. Arterial hypertension and hyperlipidemia were positive predictors of these events, while non-steroid treatment was inversely related with the incidence of cerebrovascular events.

\section{C) Small Vessel Disease}

Whether there is truly microangiopathy in patients with MELAS-syndrome remains speculative. Though there are some indications that small vessels are affected in MELASpatients, no patients with myopathy and stroke exclusively attributable to micrangiopathy have been reported so far. Nevertheless, one pathogenetic concept to explain the occurrence of SLEs relies on the speculation that MELASsyndrome is an angiopathy which also affects the cerebral arteries and subsequently causes ischemia. Small vessel disease may also occur in HIV-infection, which may not only go along with myositis but also with endothelial dysfunction and hyperlipidemia.

\section{D) Stroke of Other Determined Etiology}

In a single patient with DMD but without a history of atrial fibrillation or heart failure ischemic stroke occurred due to embolisation of an intracardiac thrombus [7]. The cause of thrombus formation in this patient, however, remained elusive. In a single patient with Kearns-Sayre syndrome acute stroke occurred due to embolisation from a thrombus within the left atrial appendage [35]. In two patients with spontaneous dissection of the internal carotid artery resulting in ischemic stroke, muscle biopsy revealed ragged-red fibers, severely decreased succinate dehydrogenase and cytochrome-c-oxidase stains, and blood chemical investigations revealed increased resting lactate [36]. Despite 
the absence of the m.3243A $>$ G mutation, MELAS-syndrome was suspected [36]. Since patients with myopathy often develop arrhythmias, they may also require implantation of a device, which is associated with the risk of embolic stroke. A rare secondary cause of stroke in myopathies may be hyperviscosity resulting from immunoglobulin therapy for myositis. If patients with polymyositis receive plasma exchange arterial hypotension resulting in low-flow infarcts may be a possible side effect.

\section{E) Ischemic Stroke of Undetermined Etiology (Crypto- genic Stroke)}

Cryptogenic stroke has been reported in a number of patients with myopathy. Recurrent pontine stroke was reported in a 4yo DMD patient. Left ventricular function was normal and there was no indication of atrial fibrillation [37]. In this case the diagnosis of DMD was uncertain since immunehistochemistry and genetic testing for dystrophin were not available at the time of diagnosis. TIA manifesting for two hours as aphasia and right-sided hemi-syndrome occurred in a 41yo male with MD1 [38]. Though the authors attributed the cerebrovascular event to mitral valve prolapse syndrome, the proposed causal relation remains questionable. In a patient with autosomal dominant Emery-Dreyfuss muscular dystrophy a fatal stroke-like episode at age $43 y$ was reported [39].

\section{STROKE-LIKE EPISODES}

SLEs are episodic events predominantly in MIDs, which characteristically spread and recur, and mimic ischemic stroke clinically to some extent but not on imaging studies [40]. So far, SLEs have been reported in MELAS-syndrome, MERRF-syndrome, Kearns-Sayre syndrome, Saguenay-Lac St. Jean cytochrome oxidase deficiency [41], and Leigh syndrome [42]. Interestingly, SLEs have been also reported in non-mitochondrial disease, such as Emery-Dreyfuss muscular dystrophy [42], congenital glycosilation disorder 1a
[43], X-linked HMSN1A [44], Jacob-Creutzfeld disease [45], proprionyl-CoA carboxylase deficiency [46], Sneddon syndrome [47], or cystinosis [48]. Most frequently SLEs occur in MELAS-syndrome of which they are an integral part of the phenotype. SLEs fundamentally differ from ischemic stroke also with regard to treatment, and prognosis (Table 5) [49].

\section{Clinical Presentation}

In accordance with ischemic stroke, SLEs may manifest as hemiparesis or aphasia. Contrary to ischemic stroke, stroke-like episodes may be associated with visual impairment other than hemianopsia, migraine or migraine-like headache, seizures (non-convulsive epileptic state, repetitive complex partial seizures, tonic clonic seizures), ataxia, blurred vision, phasic alertness, amnesia, cognitive impairment, dementia, confusional state, hallucinations, psychosis, or coma $[49,50]$. Frequently, presenting manifestations include headache, followed by hemianopsia, psychosis, aphasia, and seizures [51]. Other presenting symptoms may include gaze deviation, mental state changes, tremor, seizures, weakness, aphasia, or sensory, visual or hearing disturbance [2].

\section{Imaging}

The equivalent of SLEs on imaging are stroke-like lesions (SLLs), which present as hyperintensity on T2, DWI, and apparent diffusion coefficient (ADC) maps, and hypoperfusion on perfusion weighted imaging (PWI) in the acute stage (Table 5) indicating vasogenic edema [52]. In most cases, however, there is coexistence of cytotoxic (DWI: hyperintense, ADC: hypointense, intracellular edema) and vasogenic edema (DWI: hyperintense, ADC: hyperintense, extracellular edema) within the same SLL $[2,43]$, particularly at onset of a SLE [53]. In single cases the entire lesion may be hypointens on ADC. The cytotoxic edema was speculated to derive from gradually evolving metabolic cell death [2].

Table 5. Ischemic Stroke Compared to Stroke-like Episode [2,155]

\begin{tabular}{|c|c|c|}
\hline & Ischemic stroke & Stroke-like epsiode \\
\hline \multicolumn{3}{|c|}{ Acute stage $(<6 \mathrm{~h})$} \\
\hline $\mathrm{T} 2$ & Normal & Swelling, subtle hyperintensity \\
\hline DW & Hyperintensity, vascular territory & Hyperintensity outside vascular territory \\
\hline $\mathrm{ADC}$ & Hypointense & Hypo- and hyperintensity \\
\hline PWI & Hypoperfusion & Hyperperfusion \\
\hline $\mathrm{T} 2$ & Hyperintens & Hyperintens \\
\hline DWI & Hyperintens & Hyperintens \\
\hline \multirow[t]{2}{*}{$\mathrm{ADC}$} & Hypointensity & White matter hypointens \\
\hline & & Cortex: hyperintens \\
\hline \multicolumn{3}{|c|}{ Chronic stage } \\
\hline FLAIR & Hyperintensity, atrophy & Hyperintensity, atrophy, \\
\hline PWI & Normo- hypoperfusion & Hypoperfusion \\
\hline \multicolumn{3}{|c|}{ Laminar cortical necrosis } \\
\hline
\end{tabular}


Hyperperfusion in the acute stage has been also shown by HMPAO-SPECT, xenon-CT, and PET studies [51,52,54,55, 56]. In the subacute stage, $\mathrm{T} 2$ and DWI are hyperintense [51]. The ADC may be hyperintense in the cortex but hypointense in the subcortical white matter (Table 5). During the chronic stage atrophy, cysts, or laminar cortical necrosis may develop, and the SLL may become hyperintense on T2 and ADC but may show hypoperfusion on PWI (Table 5) $[2,54,57]$. Conventional angiography or MRA are usually normal in patients with SLEs [58]. SLLs usually persist for weeks or even months but may suddenly disappear even after years [59]. Contrary to ischemic stroke, SLLs are not confined to a vascular territory. Most frequently they are located in the parieto-occipital region and show a characteristic dynamic spread to other homo- or contralateral cortical or subcortical regions $[2,40]$. Some of the lesions disappear after a couple of weeks, whereas others newly develop or persist [2].

\section{MR-spectroscopy}

Hydrogen-MR-spectroscopy (H-MRS) of a SLL may show a reduced $\mathrm{N}$-acetyl-aspartate (NAA)/creatine $(\mathrm{Cr})$ ratio and an increased lactate-peak $[51,60]$. In the later stages of a SLL the NAA/Cr ratio may gradually increase together with the increase of the ADC [2,51]. In single patients the increase in lactate and glucose and the decrease of NAA, glutamate, or creatine is not restricted to the SLL but may occur ubiquitously within the brain [61].

\section{Pathogenesis}

SLEs are usually non-ischemic events, characterized by increased capillary permeability, hyperperfusion, neuronal hyperexcitability, and neuronal loss [62]. Though the pathogenesis of SLEs is controversial, there is largely consensus that SLLs represent a vasogenic edema [62]. Vasogenic edema may be attributable to mitochondrial microangiopathy, resulting in hypoxia and capillary leakage [63]. Arguments against mitochondrial angiopathy, however, are that the prevalence of ischemic stroke is not increased in MIDs with SLEs, that ischemic lesions within SLLs are rare, that MID patients with SLEs usually lack mitochondrial angiopathy on autopsy, and that there is hyperperfusion during the acute stage of a SLE $[2,40,55,56]$. Arguments for mitochondrial angiopathy are that SLLs occasionally also include areas of cytotoxic edema and that COX-deficiency and heteroplasmy rates are highest in leptomeningeal or cortical arteries [64]. There is also one report about a MELAS patient who exhibited a segmental narrowing of the crural segment of the right posterior cerebral artery during the SLE [65]. According to a second hypothesis, SLLs are due to focal disturbance of the energy production resulting in anaerobic metabolism, neuronal damage, or death from acidosis [40], and consecutively hyperperfusion and vasogenic edema [51]. A third hypothesis explains SLLs by focal neuronal hyperexcitability, demanding increased provision of energy, and resulting in a mismatch between demand and availability of energy [54,66]. An argument in favor of the "epilepsy" hypothesis is that focal epileptiform discharges are recorded in up to $80 \%$ of the patients during a SLE [67].

\section{Treatment}

Treatment of SLEs can be generally causal or non-causal (symptomatic) [49,67]. Since the pathogenic mechanism underlying SLEs remains elusive, a causative treatment is not yet available [68]. Thus, only symptomatic measures can be offered. Among the various symptomatic measures applied for MIDs (drugs, hemodialysis, invasive measures, surgical therapy, dietary measures, physiotherapy), specific and non-specific drug therapy is generally available for the management of SLEs, with the restriction that evidence for the effectivity of a specific or non-specific drug treatment has not been provided by appropriately designed studies. Symptomatic drug treatment of SLEs include antiepileptic treatment if SLEs are accompanied by seizures, analgetic treatment if SLEs are accompanied by headache [69], or anti-psychotic or sedative therapy if SLEs are dominated by confusion, agitation, anxiety, hyperactivity, or psychosis. Non-specific drug therapy includes drugs, which remove noxious metabolites, such as antioxidants or lactate lowering agents, electron donors/acceptors, alternative energy providers, cofactors, or other agents. The classification is partially insufficient since some agents have both an antioxidative effect and are effective at the same time as electron donors/acceptors or cofactors of respiratory chain functions. Drugs with overlapping effect include riboflavin, vitamin C, vitamin $\mathrm{E}$, or the quinones. Non-specific drug treatment of SLLs includes application of drug cocktails which comprise coenzyme Q, idebenone, L-arginine, tocopherol nicotinate, edaravone, prednisolone, glycerol, ATP, cytochrome-c, flavin mononucleotide, thiamine diphosphate, biotin, carnitine, succinate, or dichloracetate in various combinations $[67,70]$. In some studies some of these agents were given in monotherapy, such as creatine monohydrate, cysteamine, or succinate [71]. A Cochrane review of 678 abstracts, however, did not provide evidence that coenzyme Q, creatinemonohydrate, dichloracetate, or dimethylglycine are generally effective in MIDs [72]. During recent years some evidence emerged from Japanese studies that L-arginine has a beneficial effect in SLEs $[68,73,74]$. According to these studies Larginine is applied in a dosage of $0.5 \mathrm{~g} / \mathrm{kg}$ body weight intravenously during the acute stage, followed by oral application thereafter. L-arginine has been shown to be effective even if SLEs manifest as epileptic activity [73]. Occasionally, Larginine is given together with steroids, glycerol and edaravone [74]. Even steroids in monotherapy have been shown beneficial in single cases [75].

\section{Outcome}

In the majority of the cases patients recover, either to the level prior to the SLE or to a lower level. Depending of the manifestations of the SLE, the residual abnormalities may include one or several of the acute stage. If a SLE is associated with severe lactacidosis or intractable seizure activity, its outcome is potentially fatal [59].

\section{CONCLUDING REMARKS}

Ischemic stroke should be recognized as a potential manifestation of a myopathy. Stroke occurs most frequently in dystrophinopathies and myotonic dystrophy. The frequency 
of stroke in myopathies is most likely underestimated since patients with myopathy are hardly systematically screened for cardiac involvement, since these patients do not undergo regular follow-ups, and since clinical deterioration in these patients is often attributed exclusively to the muscle disease itself. Stroke in myopathy may be also not expected because of absent classical risk factors for stroke (cryptogenic stroke). A strong disadvantage of most descriptions about myopathic patients with risk factors for stroke is the lack of a regular follow-up. Due to these insufficiencies myopathy patients should be systematically referred to the cardiologist. Early cardiac treatment, if indicated, may significantly improve the outcome of these patients, if the measures taken follow the available recommendations. SLEs predominantly occur in patients with MIDs, most frequently in MELASsyndrome, and are much more frequent than ischemic stroke in patients with myopathy. SLEs should be early recognized and unequivocally delineated from ischemic stroke to initiate appropriate measures. Particularly if SLEs are associated with seizures their outcome can be strongly improved if adequate antiepileptic treatment is effective. Overall, neurologists need to become aware of the potential association between myopathy and cerebrovascular events, which need to be clearly delineated from SLEs indicating a MID. Since no effective therapy is available yet, all effort should be directed towards research on the development of targeting, safe and immediately effective agents.

\section{ABBREVIATIONS}

$\begin{array}{lll}\mathrm{ADC} & =\text { Apparent diffusion coefficient maps } \\ \mathrm{CMP} & =\text { Cardiomyopathy } \\ \mathrm{DMD} & =\text { Duchenne muscular dystrophy } \\ \mathrm{DWI} & =\text { Diffusion weighted imaging } \\ \mathrm{EF} & =\text { Ejection fraction } \\ \mathrm{HMSN} & =\text { Hereditary motor and sensory neuropathy } \\ \mathrm{IVIG} & =\text { Intravenous immunoglobulines } \\ \text { LVHT } & =\begin{array}{l}\text { Left ventricular hypertrabeculation/non- } \\ \text { compaction }\end{array}\end{array}$

MELAS $=$ Mitochondrial encephalopathy, lactacidosis, and SLE-syndrome

MID $=$ Mitochondrial disorder

MRI = Magnetic resonance imaging

$\mathrm{OAC}=$ Oral anticoagulation

PWI = Perfusion-weighted imaging

SLE $=$ Stroke-like episode

$\mathrm{SLL}=$ Stroke-like lesion

SPECT $=$ Singlephoton emission computed tomography

TOAST $=$ Trial of Org 10172 in Acute Stroke Treatment

\section{CONFLICT OF INTEREST}

None declared.

\section{ACKNOWLEDGEMENTS}

None declared.

\section{REFERENCES}

[1] Yatsu FM. Strokes in Asians and Pacific-Islanders, Hispanics, and Native Americans. Circulation 1991; 83: 1471-2.

[2] Kim JH, Lim MK, Jeon TY, et al. Diffusion and perfusion characteristics of MELAS (mitochondrial myopathy, encephalopathy, lactic acidosis, and stroke-like episode) in thirteen patients. Korean $\mathrm{J}$ Radiol 2011; 12: 15-24.

[3] Adams HP Jr, Bendixen BH, Kappelle LJ, et al. Classification of subtype of acute ischemic stroke. Definitions for use in amulticenter clinical trial.TOAST.Trial of Org 10172 in Acute Stroke Treatment. Stroke 1993; 24: 35-41.

[4] Finsterer J, Stollberger C. Stroke in myopathies. Cerebrovasc Dis 2010; 29: 6-13.

[5] Finsterer J. Mitochondrial disorder overlapping with aorto-iliac occlusive disease (Leriche syndrome). Scott Med J 2008; 53: 65-71.

[6] Tay SH, Nordli DR Jr, Bonilla E, et al. Aorticrupture in mitochondrial encephalopathy, lactic acidosis, and stroke-likeepisodes. Arch Neurol 2006; 63: 281-3.

[7] Gimenez-Muñoz A, Capablo JL, Alarcia R, Torné L, Errea JM. Intracardiacthrombus and cerebral infarction in a patient with Duchenne muscular dystrophy. J Clin Neuromuscul Dis 2009; 11: 79-80.

[8] Boriani G, Gallina M, Merlini L, et al. Clinical relevance of atrial fibrillation/flutter, stroke, pacemaker implant, and heart failure in Emery-Dreifuss muscular dystrophy: a long-term longitudinal study. Stroke 2003; 34: 901-8.

[9] Atsumi M, Tanaka A, Kawarabayashi T, et al. Cerebral embolism associated with Becker muscular dystrophy-related dilated cardiomyopathy. No to Shinkei 2004; 56: 163-7.

[10] Hanajima R, Kawai $M$. Incidence of cerebral infarction in Duchenne muscular dystrophy. Muscle Nerve 1996; 19: 928.

[11] Cook AW, Bird TD, Spence AM, Pagon RA, Wallace JF. Myotonic dystrophy, mitral-valve prolapse, and stroke.Lancet 1978; $1: 335-6$.

[12] Biller J, Ionasescu V, Zellweger H, Adams HP Jr, Schultz DT. Frequency ofcerebral infarction in patients with inherited neuromuscular diseases. Stroke 1987; 18: 805-7.

[13] Wahbi K, Meune C, Bécane HM, et al. Left ventricular dysfunction and cardiac arrhythmias arefrequent in type 2 myotonic dystrophy: a case control study. Neuromuscul Disord 2009; 19: 468-72.

[14] Finsterer J, Stöllberger C, Avanzini M, Rauschka H. Restrictive cardiomyopathy in dermatomyositis. Scand J Rheumatol 2006; 35: 229-32.

[15] Nodari S, Triggiani M, Campia U, Manerba A, et al. Effects of n-3 polyunsaturated fatty acids on left ventricular function and functional capacity in patients with dilated cardiomyopathy. J Am Coll Cardiol 2011; 57: 870-9.

[16] Ikeniwa C, Sakai M, Kimura S, Wakayama T, et al. Two cases of Duchenne muscular dystrophy complicated with dilated cardiomyopathy and cerebral infarction. No To Shinkei 2006; 58: 250-5.

[17] Díaz Buschmann C, Ruiz Falcó ML, Tamariz Martel Moreno A, et al. Repeated cerebral infarction in a patient with Duchenne's muscular dystrophy. Rev Neurol 2004; 38: 533-6.

[18] Ances BM, Sullivan J, Weigele JB, et al. Stroke associated with Barth syndrome. J Child Neurol 2006; 21: 805-7.

[19] Chin TK, Perloff JK, Williams RG, Jue K, Mohrmann R. Isolated noncompaction of left ventricular myocardium. A study of eight cases. Circulation 1990; 82: 507-13.

[20] Engberding R, Bender F. Identification of a rare congenital anomaly of the myocardium by two-dimensional echocardiography: persistence of isolated myocardial sinusoids. Am J Cardiol 1984; 53 : 1733-4.

[21] Stöllberger C, Finsterer J. Left ventricular hypertrabeculation/ noncompaction. J Am Soc Echocardiogr 2004; 17: 91-100.

[22] Finsterer J. Cardiogenetics, neurogenetics, and pathogenetics of left ventricular hypertrabeculation/ noncompaction. Pediatr Cardiol 2009; 30: 659-81.

23] Fazio G, Corrado G, Zachara E, et al. Anticoagulant drugs in noncompaction: a mandatory therapy? J Cardiovasc Med (Hagerstown) 2008; 9: 1095-7. 
[24] Finsterer J, Stollberger C, Mölzer G, Winkler-Dworak M, Blazek G. Cerebrovascular events in left ventricular hypertrabeculation/noncompaction with and without myopathy. Int J Cardiol 2008; 130: 344-8.

[25] Stöllberger C, Finsterer J. Left ventricular hypertrabeculation/ noncompaction and stroke or embolism. Cardiology 2005; 103: 6872

[26] Fazio G, Novo G, Visconti C, et al. An unusual cause of cerebral cardioembolism in a 33-year-old man due to ventricular noncompaction. Neurologist 2009; 15: 51-2.

[27] Oduncu V, Akgun T, Erkol A, Mutlu B. Biventricular noncompaction presenting with stroke. Eur J Cardiothorac Surg 2008; 33: 737.

Sahin S, Karsidag S. An unusual cause of cardioembolic stroke: isolated left ventricular noncompaction. Neurologist 2009; 15: 51.

[29] Sir JJ, Lee B, Nah JC, et al. Serious cardioembolic stroke resulting from an overlooked left ventricular noncompaction. South Med J 2008; 101: 969-70.

[30] Iizuka T, Goto Y, Miyakawa S, et al. Progressive carotid artery stenosis with a novel tRNA phenylalanine mitochondrial DNA mutation. J Neurol Sci 2009; 278: 35-40.

[31] Suwa A, Hirakata M, Kaneko Y, Sato S, Suzuki Y, Kuwana M. Successful treatment of refractory polymyositis with the immunosuppressant mizoribine: case report. Clin Rheumatol 2009; 28: 2279.

[32] Regan M, Haque U, Pomper M, Pardo C, Stone J. Central nervous system vasculitis as a complication of refractory dermatomyositis. $\mathrm{J}$ Rheumatol 2001; 28: 207-11.

[33] White DA, Leonard MC. Acute stroke with high-dose intravenous immune globulin. Am J Health Syst Pharm 2007; 64: 1611-4.

[34] Sherer Y, Livneh A, Levy Y, Shoenfeld Y, Langevitz P. Dermatomyositis and polymyositis associated with the antiphospholipid syndrome-a novel overlap syndrome. Lupus 2000; 9: 42-6.

[35] Kosinski C, Mull M, Lethen H, Töpper R. Evidence for cardioembolic stroke in a case of Kearns-Sayre syndrome. Stroke 1995; 26 : 1950-2.

[36] Kalashnikova LA, Sakharova AV, Dobrynina LA, et al. Mitochondrial arteriopathy as a cause of spontaneous dissection of cerebral arteries. Zh Nevrol Psikhiatr Im S S Korsakova 2010; 110 (Suppl 2): $3-11$.

[37] Matsuishi T, Yano E, Terasawa K, et al. Basilar artery occlusion in a case of Duchenne muscular dystrophy. Brain Dev 1982; 4: 37984.

[38] Morris LK, Cuetter AC, Gunderson CH. Myotonic dystrophy, mitral valve prolapse, and cerebral embolism. Stroke 1982; 13: 934.

[39] Liang WC, Yuo CY, Liu CY, et al. Novel LMNA mutation in a Taiwanese family with autosomal dominant Emery-Dreifuss muscular dystrophy. J Formos Med Assoc 2007; 106(suppl. 2): S27-31.

[40] Oppenheim C, Galanaud D, Samson Y, et al. Can diffusion weighted magnetic resonance imaging help differentiate stroke from stroke-like events in MELAS? J Neurol Neurosurg Psychiatry 2000; 69: 248-50.

[41] Morin C, Dubé J, Robinson BH, et al. Stroke-like episodes in autosomal recessive cytochrome oxidase deficiency. Ann Neurol 1999; 45: 389-92.

[42] Furuya H, Sugimura T, Yamada T, Hayashi K, Kobayashi T. A case of incomplete Kearns-Sayre syndrome with a stroke like episode. Rinsho Shinkeigaku 1997; 37: 680-4.

[43] Ishikawa N, Tajima G, Ono H, Kobayashi M. Different neuroradiological findings during two stroke-like episodes in a patient with a congenital disorder of glycosylation type Ia. Brain Dev 2009; 31 : 240-3.

[44] Anand G, Maheshwari N, Roberts D, et al. X-linked hereditary motor sensory neuropathy (type 1) presenting with a stroke-like episode. Dev Med Child Neurol 2010; 52: 677-9.

[45] Kamogawa K, Toi T, Okamoto K, Okuda B. A case of CreutzfeldtJakob disease with stroke-like episode as an initial symptom. Nippon Ronen Igakkai Zasshi 2009; 46: 458-61.

[46] Scholl-Bürgi S, Haberlandt E, Gotwald T, et al. Stroke-like episodes in propionic acidemia caused by central focal metabolic decompensation. Neuropediatrics 2009; 40: 76-81.

[47] Wheeler PG, Medina S, Dusick A, Bull MJ, Andreoli SP, EdwardsBrown M. Livedo reticularis, developmental delay and stroke-likeepisode in a 7-year-old male. Clin Dysmorphol 1998; 7: 69-74.
[48] Broyer M, Tête MJ, Guest G, Berthélémé JP, Labrousse F, Poisson M. Clinical polymorphism of cystinosis encephalopathy. Results of treatment with cysteamine. J Inherit Metab Dis 1996; 19: 65-75.

[49] Finsterer J. Management of mitochondrial stroke-like episodes.Eur J Neurol 2009; 16: 1178-84

[50] Sartor H, Loose R, Tucha O, Klein HE, Lange KW. MELAS: a neuropsychological and radiological follow-up study. Mitochondrial encephalomyopathy, lactic acidosis and stroke. Acta Neurol Scand 2002; 106: 309-13.

[51] Iizuka T, Sakai F, Kan S, Suzuki N. Slowly progressive spread of the stroke-like lesions in MELAS. Neurology 2003; 61: 1238-44.

[52] Ito H, Mori K, Harada M, et al. Serial brain imaging analysis of stroke-like episodes in MELAS. Brain Dev 2008; 30: 483-8.

[53] Tzoulis C, Bindoff LA.Serial diffusion imaging in a case of mitochondrial encephalomyopathy, lactic acidosis, and stroke-like episodes. Stroke 2009; 40: e15-7.

[54] Iizuka T, Sakai F, Suzuki N, et al. Neuronal hyperexcitability in stroke-like episodes of MELAS syndrome. Neurology 2002; 59: 816-24.

[55] Nariai T, Ohno K, Akimoto H, et al. Cerebral blood flow, vascular response and metabolism in patients with MELAS syndrome - xenon CT and PET study. Keio J Med 2000; 49(suppl 1): A68-70.

[56] Takahashi S, Tohgi H, Yonezawa H, Obara S, Nagane Y. Cerebral blood flow and oxygen metabolism before and after a stroke-like episode in patients with mitochondrial myopathy, encephalopathy, lactic acidosis and stroke-like episodes (MELAS). J Neurol Sci 1998; 158: 58-64.

[57] Li JY, Hsieh RH, Peng NJ, et al.A follow-up study in a Taiwanese family with mitochondrial myopathy, encephalopathy, lactic acidosis and stroke-like episodes syndrome. J Formos Med Assoc 2007; 106: 528-36.

[58] Klein A, Fasnacht M, Huisman TA, Neuhaus TJ, Martin E, Boltshauser E. Siblings with infantile cerebral stroke and delayed multivessel involvement - a new hereditary vasculopathy? Eur J Paediatr Neurol 2007; 11: 292-6.

[59] Finsterer J, Barton P. Regression of stroke-like lesions in MELASsyndrome after seizure control. Epileptic Disord 2010; 12: 330-4.

[60] Pavlakis SG, Kingsley PB, Kaplan GP, Stacpoole PW, O'Shea M, Lustbader D. Magnetic resonance spectroscopy: use in monitoring MELAS treatment. Arch Neurol 1998; 55: 849-52.

[61] Wilichowski E, Pouwels PJ, Frahm J, Hanefeld F. Quantitative proton magnetic resonance spectroscopy of cerebral metabolic disturbances in patients with MELAS. Neuropediatrics 1999; 30: 25663.

[62] Iizuka T. Pathogenesis and treatment of stroke-like episodes in MELAS. Rinsho Shinkeigaku 2008; 48: 1006-9.

[63] Takahashi N, Shimada T, Murakami Y, et al. Vascular involvement in a patient with mitochondrial myopathy, encephalopathy, lactic acidosis, and stroke-like episodes. Am J Med Sci 2005; 329: 265-6.

[64] Betts J, Jaros E, Perry RH, et al. Molecular neuropathology of MELAS: level of heteroplasmy in individual neurones and evidence of extensive vascular involvement. Neuropathol Appl Neurobiol 2006; 32: 359-73.

[65] Noguchi A, Shoji Y, Matsumori M, Komatsu K, Takada G. Strokelike episode involving a cerebral artery in a patient with MELAS. Pediatr Neurol 2005; 33: 70-1.

[66] Iizuka T, Sakai F, Ide T, Miyakawa S, Sato M, Yoshii S. Regional cerebral blood flow and cerebrovascular reactivity during chronic stage of stroke-like episodes in MELAS - implication of neurovascular cellular mechanism. J Neurol Sci 2007; 257: 126-38.

[67] Finsterer J. Treatment of mitochondrial disorders. Eur J Paediatr Neurol 2010; 14: 29-44

[68] Koga Y, Povalko N, Nishioka J, Katayama K, Kakimoto N, Matsuishi T. MELAS and L-arginine therapy: pathophysiology of stroke-like episodes. Ann N Y Acad Sci 2010; 1201: 104-10.

[69] Iizuka T, Sakai F, Endo M, Suzuki N. Response to sumatriptan in headache of MELAS syndrome. Neurology 2003; 61: 577-8.

[70] Santa KM. Treatment options for mitochondrial myopathy, encephalopathy, lacticacidosis, and stroke-like episodes (MELAS) syndrome. Pharmacotherapy 2010; 30: 1179-96.

[71] DiMauro S, Rustin P. A critical approach to the therapy of mitochondrial respiratory chain and oxidative phosphorylation diseases. Biochim Biophys Acta 2009; 1792: 1159-67.

[72] Chinnery P, Majamaa K, Turnbull D, Thorburn D. Treatment for mitochondrial disorders. Cochrane Database Syst Rev 2006; 1: CD004426. 
[73] Toribe Y, Tominaga K, Ogawa K, Suzuki Y. Usefulness of Larginine infusion for status epilepticus in mitochondrial myopathy, encephalopathy, lactic acidosis, and stroke-like episodes. No To Hattatsu 2007; 39: 38-43.

[74] Kubota M, Sakakihara Y, Mori M, Yamagata T, Momoi-Yoshida M. Beneficial effect of L-arginine for stroke-like-episode in MELAS. Brain Dev 2004; 26: 481-3.

[75] Rossi FH, Okun M, Yachnis A, Quisling R, Triggs WJ. Corticosteroid treatment of mitochondrial encephalomyopathies. Neurologist 2002; 8: 313-5.

[76] Madej-Pilarczyk A, Kmieć T, Fidziańska A, et al. Progeriacaused by a rare LMNA mutation $\mathrm{p} . \mathrm{S} 143 \mathrm{~F}$ associated with mild myopathy and atrialfibrillation. Eur J Paediatr Neurol 2008; 12: 427-30.

[77] Hershberger RE, Cowan J, Morales A. $<\mathrm{i}>$ LMNA $</ \mathrm{i}>$-Related Dilated Cardiomyopathy. 2008 Jun 12. In: Pagon RA, Bird TC, Dolan CR, Stephens K, editors. Gene Reviews [Internet]. Seattle (WA): University of Washington, Seattle; 1993-. Available from http: //www.ncbi.nlm.nih.gov/bookshelf/br.fcgi?book=gene\&part= dcm-lmna

[78] Brauch KM, Chen LY, Olson TM. Comprehensive mutation scanning of LMNA in 268patients with lone atrial fibrillation. Am J Cardiol 2009; 103: 1426-8.

[79] Otomo J, Kure S, Shiba T, et al. Electrophysiological andhistopathological characteristics of progressive atrioventricular blockaccompanied by familial dilated cardiomyopathy caused by a novel mutation oflamin A/C gene. J Cardiovasc Electrophysiol 2005; 16: 137-45.

[80] Yuan WL, Huang CY, Wang JF, et al. R25G mutation in exon 1 of LMNA gene is associated with dilatedcardiomyopathy and limbgirdle muscular dystrophy 1B. Chin Med J (Engl) 2009; 122: 28405 .

[81] van Berlo JH, de Voogt WG, van der Kooi AJ, et al. Meta-analysis of clinical characteristics of 299 carriers of LMNA gene mutations: do lamin $\mathrm{A} / \mathrm{C}$ mutations portend a high risk of sudden death? J Mol Med 2005; 83: 79-83.

[82] Brenner R, Joerg L, Rickli H. Myotonic dystrophy as a potential killer. Acta Cardiol 2009; 64: 567-9.

[83] Eroğlu S, Ozin B, Ozbiçer S, Müderrisoğlu H.A case of myotonic dystrophy presenting with ventricular tachycardia and atrial fibrillation.Turk Kardiyol Dern Ars 2009; 37: 337-40.

[84] Halawa A, Iskandar SB, Brahmbhatt V, Fahrig SA. Atrial flutter and myotonicdystrophy in a male adolescent treated with radiofrequency catheter ablation. Rev Cardiovasc Med 2007 Spring; 8: $118-22$.

[85] Stevenson WG, Perloff JK, Weiss JN, Anderson TL. Facioscapulohumeral muscular dystrophy: evidence for selective, genetic electrophysiologic cardiacinvolvement. J Am Coll Cardiol 1990; 15: 292-9.

[86] Melberg A, Oldfors A, Blomstrom-Lundqvist C, et al. Autosomaldominant myofibrillar myopathy with arrhythmogenic right ventricularcardiomyopathy linked to chromosome 10q. Ann Neurol 1999; 46: 684-92.

[87] Abraham SC, DeNofrio D, Loh E, et al. Desmin myopathy involving cardiac, skeletal, and vascular smooth muscle: report of a case with immunoelectron microscopy. Hum Pathol 1998; 29: 876-82.

[88] Vernengo L, Chourbagi O, Panuncio A, et al. Desmin myopathy with severe cardiomyopathy in a Uruguayan familydue to a codon deletion in a new location within the desmin $1 \mathrm{~A}$ rod domain. Neuromuscul Disord 2010; 20: 178-87.

[89] Takahashi M, Nakamura M, Yamaoka Y, Nakano S, Akiguchi I. A case of rigidspine syndrome with congenital cardiac abnormality of sinus venosus defect. Rinsho Shinkeigaku 1995; 35: 204-7.

[90] Spinazzi M, Fanin M, Melacini P, Nascimbeni AC, Angelini C. Cardioembolicstroke in Danon disease. Clin Genet 2008; 73: 38890

[91] Danek A, Rubio JP, Rampoldi L, Ho M, Dobson-Stone C, Tison F. McLeodneuroacanthocytosis: genotype and phenotype. Ann Neurol 2001; 50: 755-64

[92] Jung HH, Danek A, Frey BM. McLeod syndrome: a neurohaematological disorder. Vox Sang 2007; 93: 112-21.

[93] Finsterer J, Ramaciotti C, Wang $\mathrm{CH}$, et al. Cardiac findings in congenital muscular dystrophies. Pediatrics 2010; 126: 538-45.

[94] Soliman OI, van der Beek NA, van Doorn PA, et al. Cardiac involvement in adults withPompe disease. J Intern Med 2008; 264: 333-9.
[95] Finsterer J. Recurrent pancreatitis as a manifestation of multisystem mitochondrial disorder. Minerva Gastroenterol Dietol 2007; 53: 285-9.

[96] Banwell BL, Becker LE, Jay V, Taylor GP, Vajsar J. Cardiac manifestations ofcongenital fiber-type disproportion myopathy. J Child Neurol 1999; 14: 83-7.

[97] Celik C, Uysal H, Heper AO, karaoglan B. epidermolysis Bullosa simplex associated with muscular dystrophy and cardiac involvement. J Clin Neuromuscul Dis 2005; 6: 157-61.

[98] Sainte-Beuve C, Victor J, Penisson I, Tadei A. Arrhythmia and conductiondefects in polymyositis. Arch Mal Coeur Vaiss 1994; 87: 1241-5.

[99] Altman A, Szyper-Kravitz M, Shoenfeld Y. Colchicine-induced rhabdomyolysis. Clin Rheumatol 2007; 26: 2197-9.

100] Mahitchi E, Balagué F, Waldburger M. What is your diagnosis.Myopathy due to hypothyroidism aggravated by amiodarone. Praxis (Bern 1994) 2009; 98: 999-1000.

[101] Coppola G, Bützberger S, Greminger P, Schulthess G. Muscle weakness. Praxis (Bern 1994) 2003; 92: 236-40.

[102] Cox GF, Kunkel LM. Dystrophies and heart disease. Curr Opin Cardiol 1997; 12: 329-43.

[103] Boito CA, Melacini P, Vianello A, Prandini P, Gavassini BF, Bagattin A. Clinical and molecular characterization of patients with limb-girdle muscular dystrophy type 2I. Arch Neurol 2005; 62: 1894-9.

[104] Muller T, Krasnianski M, Witthaut R, Deschauer M, Zierz S. Dilated cardiomyopathy may be an early sign of the C826A Fukutin-related protein mutation. Neuromuscul Disord 2005; 15: 3726.

[105] Ben Yaou R, Gueneau L, Demay L, Stora S, Chikhaoui K, Richard $\mathrm{P}$. Heart involvement in lamin $\mathrm{A} / \mathrm{C}$ related diseases. Arch Mal Coeur Vaiss 2006; 99: 848-55.

[106] Fujimori Y, Okimatsu H, Kashiwagi T, et al.. Molecular defects associated with antithrombin deficiency and dilated cardiomyopathy in a Japanese patient. Intern Med 2008; 47: 925-31.

[107] Volpi L, Ricci G, Passino C, et al. Prevalent cardiac phenotype resulting in heart transplantation in a novel LMNAgene duplication. Neuromuscul Disord 2010; 20: 512-6.

[108] Hermans MC, Pinto YM, Merkies IS, de Die-Smulders CE, Crijns HJ, Faber CG. Hereditary muscular dystrophies and the heart. Neuromuscul Disord 2010; 20: 479-92.

[109] Bourteel H, Stojkovic T, Cuisset JM, et al. Phenotypic aspects of FKRP-linked muscular dystrophy type 2I in aseries of eleven patients. Rev Neurol (Paris) 2007; 163: 189-96.

[110] Murakami T, Hayashi YK, Noguchi S, Ogawa M, Nonaka I, Tanabe Y. Fukutin gene mutations cause dilated cardiomyopathy with minimal muscle weakness. Ann Neurol 2006; 60: 597-602.

[111] Jones KJ, Morgan G, Johnston H, T et al. The expanding phenotype of laminin alpha2 chain (merosin) abnormalities: caseseries and review. J Med Genet 2001; 38: 649-57.

[112] Selcen D, Engel AG. Mutations in ZASP define a novel form of muscular dystrophy in humans. Ann Neurol 2005; 57: 269-76.

[113] Wilke A, Schönian U, Herzum M, et al. The extracellular matrix and cytoskeleton of the myocardium in cardiac inflammatory reaction. Herz 1995; 20: 95-108.

[114] Sugimoto S. A novel vacuolar myopathy with dilated cardiomyopathy. Autophagy 2007; 3: 638-9.

[115] Sugie K, Yamamoto A, Murayama K, Oh SJ, Takahashi M, Mora M. Clinicopathological features of genetically confirmed Danon disease. Neurology 2002; 58: 1773-8.

[116] DeAdamo P, Fassone L, Gedeon A, Janssen EAM, Bione S, Bolhuis PA. The X-linked gene G4.5 is responsible for different infantile dilated cardiomyopathies. Am J Hum Genet 1997; 61: 862-7.

[117] Spencer CT, Bryant RM, Day J, Gonzalez IL, Colan SD, Thompson WR. Cardiac and clinical phenotype in Barth syndrome. Pediatrics 2006; 118: e337-46.

[118] Jeren-Strujić B, Jeren T, Thaller N, Zivković Z, Raos V. A case of McLeod syndrome with chronic renal failure. Blood Purif 1998; 16: 336-40.

[119] Windpassinger C, Schoser B, Straub V, Hochmeister S, Noor A, Lohberger B. An X-linked myopathy with postural muscle atrophy and generalizedhypertrophy, termed XMPMA, is caused by mutations in FHL1. Am J Hum Genet 2008; 82: 88-99.

[120] Schessl J, Taratuto AL, Sewry C, Battini R, Chin SS, Maiti B. Clinical,histological and genetic characterization of reducing body myopathy causedby mutations in FHL1. Brain 2009; 132: 452-64 
[121] Muller-Hocker J, Schafer S, Mandel B, Lochmuller H, Pongratz D. Nemaline cardiomyopathy in a young adult: an ultraimmunohistochemical study and review of the literature. Ultrastruct Pathol 2000; 24: 407-16

[122] Take C, Asano H, Komatsu A, Miyaji M, Iikuni K, Kowa H. An autopsy case ofdilated cardiomyopathy associated with congenital nemaline myopathy. Nihon Naika Gakkai Zasshi 2008; 97: 413-6.

[123] Michalek-Sauberer A, Gilly H. Prophylactic use of dantrolene in a patient withcentral core disease. Anesth Analg 1998; 86: 915-6.

[124] Al-Ruwaishid A, Vajsar J, Tein I, Benson L, Jay V. Centronuclear myopathy and cardiomyopathy requiring heart transplant. Brain Dev 2003; 25: 62-6.

[125] Manouvrier J, Leys D, Ducloux G, et al. Myocardiopathy disclosing a centronuclear myopathy in an adult. Ann Cardiol Angeiol (Paris) 1986; 35: 557-9.

[126] Clarke NF, Smith RL, Bahlo M, North KN. A novel X-linked form of congenitalfiber-type disproportion. Ann Neurol 2005; 58: 76772 .

[127] Fujita K, Nakano S, Yamamoto H, et al. An adult case of congenital fiber type disproportion (CFTD) with cardiomyopathy. Rinsho Shinkeigaku 2005; 45: 380-2

[128] Schroder JM, May R, Shin YS, Sigmund M, Nase-Huppmeier S. Juvenile hereditary polyglucosan body disease with complete branching enzyme deficiency (type IV glycogenosis). Acta Neuropathol (Berl) 1993; 85: 419-30.

[129] Hou JW. Primary systemic carnitine deficiency presenting as recurrent Reye-like syndrome and dilated cardiomyopathy. Chang Gung Med J 2002; 25: 832-7.

[130] Bonnet D, Rustin P, Rotig A, et al. Heart transplantation in children with mitochondrial cardiomyopathy. Heart 2001; 86: 570-3.

[131] Finsterer J. Dropped head syndrome in mitochondriopathy. Eur Spine J 2004; 13: 652-6.

[132] Kleber FX, Park JW, Hübner G, Johannes A, Pongratz D, König E. Congestive heart failure due to mitochondrial cardiomyopathy in Kearns-Sayre syndrome. Klin Wochenschr 1987; 65: 480-6.

[133] Finsterer J, Stölberger C, Kopsa W. Noncompaction in myotonic dystrophy type 1 on cardiac MRI. Cardiology 2005; 103: 167-8.

[134] Finsterer J, Gelpi E, Stöllberger C. Left ventricular hypertrabeculation / noncompaction as a cardiac manifestation of Duchenne muscular dystrophy under non-invasive positive-pressure ventilation. Acta Cardiol 2005; 60: 445-8.

[135] Vatta M, Mohapatra B, Jimenez S, et al. Mutations in cypher/ZASP in patients with dilated cardiomyopathy and left ventricular noncompaction. J Am Coll Cardiol 2003; 42: 2014-27.

[136] Hermida-Prieto M, Monserrat L, Castro-Beiras A, et al. Familial dilated cardiomyopathy and isolated left ventricular noncompaction associated with lamin A/C gene mutations. Am J Cardiol 2004; 94: $50-4$.

[137] Kenton AB, Sanchez X, Coveler KJ, et al. Isolated left ventricular noncompaction is rarely caused by mutations in G4.5, alphadystrobrevin and FK Binding Protein-12. Mol Genet Metab 2004; 82: 162-6.

[138] Thevathasan W, Squier W, Maciver DH, Hilton DA, Fathers E, Hilton-Jones D. Oculopharyngodistal myopathy - A possible asso- ciation with cardiomyopathy. Neuromuscul Disord 2011; 21: 121-

[139] Pignatelli RH, McMahon CJ, Dreyer WJ, et al. Clinical characterization of left ventricular noncompaction in children: a relatively common form of cardiomyopathy. Circulation 2003; 108: 2672-8.

[140] Finsterer J, Schoser B, Stöllberger C. Myoadenylate-deaminase gene mutation associated with left ventricular hypertrabeculation/non-compaction. Acta Cardiol 2004; 59: 453-6.

[141] Corrado G, Checcarelli N, Santarone M, Stollberger C, Finsterer J. Left ventricular hypertrabeculation/noncompaction with PMP22 duplication-based Charcot-Marie-Tooth disease type 1A. Cardiology 2006; 105: 142-5.

[142] Münkle T, Kaufmann H, Keim M. Non-compaction cardiomyopathy: A rareechocardiographic diagnosis. Dtsch Med Wochenschr 2010; 135: 639-42.

[143] Mello RP, Szarf G, Nakano E, Dietrich C, Cirenza C, Paola AA Noncompaction of the myocardium, Chagas' disease and dysfunction: a case report. Arq Bras Cardiol 2010; 95: e4-6.

[144] Stöllberger C, Finsterer J, Sodeck GH, Grassberger M, Zimpfer D. Stroke from noncompaction overlooked by echocardiography. Int $\mathrm{J}$ Cardiol 2010; 148: 357-8.

[145] Vatthyam RK, Bates JR, Waller BF. Acute cardiac and neurologic decompensation in a high school athlete. J Am Soc Echocardiogr 2009; 22: 1420.e1-3.

[146] Steffel J, Kobza R, Oechslin E, Jenni R, Duru F. Electrocardiographic characteristics at initial diagnosis in patients with isolated left ventricular noncompaction. Am J Cardiol 2009; 104: 984-9.

[147] Stanton C, Bruce C, Connolly H, et al. Isolated left ventricular noncompaction syndrome. Am J Cardiol 2009; 104: 1135-8.

[148] Baez-Escudero J, Pillai M, Nambi V, Dokainish H. Comprehensive contrast and 3-dimensional echocardiographic imaging of left ventricular noncompaction cardiomyopathy. Eur J Echocardiogr 2008; 9: $156-7$

[149] Finsterer J, Stöllberger C, Feichtinger H. Noncompaction and endocarditis in suspected mitochondrial disorder. Int J Cardiol 2008; 123: e45-7.

[150] Nakajima M, Hirano T, Doi H, Uchino M. Stroke and ventricular dysfunction in a patient with isolated left ventricular noncompaction. Intern Med 2007; 46: 1251-4.

[151] Celebi AS, Gulel O, Cicekcioglu H, Celebi OO, Ulusoy V. Isolated noncompaction of the left ventricular myocardium complicated by thromboembolic cerebrovascular accident in a patient with essential thrombocythemia. Int J Cardiol 2008; 128: e22-4.

[152] Fernández Sánchez LJ, Pérez González R, Guasch Arévalo E, Martín Reyes R, Gilsanz Rodríguez F. Perioperative treatment of a pregnant woman with recent cerebral infarction secondary to noncompaction cardiomyopathy. Rev Esp Anestesiol Reanim 2006; 53: 661-4.

[153] Walpot J, Klazen C, Sorgedrager J, Hoevenaar M, den Braber J. Isolated ventricular noncompaction in a patient with stroke. Echocardiography 2005; 22: 690-2.

[154] Hasçelik S, Yalnizoğlu D, Kafali G, et al. Stroke owing to noncompaction of myocardium. J Child Neurol 2003; 18: 437-9.

[155] Ohshita T, Oka M, Imon Y, et al. Serial diffusion-weighted imaging in MELAS. Neuroradiology 2000; 42: 651-6.

\section{(C) Josef Finsterer; Licensee Bentham Open.}

This is an open access article licensed under the terms of the Creative Commons Attribution Non-Commercial License (http://creativecommons.org/licenses/by-nc/3.0/) which permits unrestricted, non-commercial use, distribution and reproduction in any medium, provided the work is properly cited. 